\title{
The value of systematic lymphadenectomy during debulking surgery in the treatment of ovarian cancer: a meta-analysis of randomized controlled trials
}

Qingqing Lin ${ }^{1 \dagger}$, Wenchao Liur ${ }^{2 \dagger}$, Song Xu', Juan $\mathrm{Li}^{1}$ and Jinyi Tong ${ }^{1 *}$

\begin{abstract}
Background: The therapeutic value of systematic lymphadenectomy during debulking surgery for ovarian cancer remains controversial. We conduct this meta-analysis to evaluate the significance of systematic lymphadenectomy in patients treated with optimal cytoreduction for ovarian cancer.

Method: The PubMed, Medline, Embase, Cochrane Library and Web of Science databases were searched up to October 2019. Only English-language publications of randomized controlled trials (RCTs) that investigated the role of systematic lymphadenectomy in patients with ovarian cancer were selected for this analysis. For overall survival (OS) and progression-free survival (PFS), pooled hazard ratios (HR) with 95\% confidence intervals (Cls) were calculated; for complications rate, we calculated pooled risk ratio (RR) with 95\% confidence interval (CI). Statistical heterogeneity was assessed using both the $\mathrm{I}^{2}$ and chi-square tests. In cases of $\mathrm{I}^{2}$ being larger than $50 \%$, a randomeffect model was used, otherwise a fixed-effect model was used.

Results: Four RCTs involving 1607 patients were included in the present analysis. There was no difference in OS between systematic lymphadenectomy and unsystematic lymphadenectomy $(\mathrm{HR}=1.00 ; 95 \% \mathrm{Cl}=0.94,1.07 ; p=$ 0.90). Similarly, no significant difference was observed in PFS between these two groups $(\mathrm{HR}=0.97 ; 95 \% \mathrm{Cl}=0.87$, $1.08 ; p=0.62$ ). And postoperative complications occurred more frequently in the systematic lymphadenectomy group $(\mathrm{RR}=1.50 ; 95 \% \mathrm{Cl}=1.34,1.68 ; p<0.00001)$.

Conclusion: Systematic lymphadenectomy in patients with optimally cytoreduced ovarian cancer was not associated with longer overall or progression-free survival than unsystematic lymphadenectomy and was associated with a higher incidence of postoperative complications.
\end{abstract}

Keywords: Systematic lymphadenectomy, Ovarian cancer, Overall survival, Progression-free survival, Complications, Meta-analysis

\footnotetext{
* Correspondence: tongjinyi252@zju.edu.cn

${ }^{\dagger}$ Qingqing Lin and Wenchao Liu contributed equally to this work.

'Department of Gynecology, Affiliated Hangzhou First People's Hospital,

Zhejiang University School of Medicine, 261 Huansha Rd, Hangzhou City

310006, Zhejiang Province, China

Full list of author information is available at the end of the article
}

C C The Author(s). 2020 Open Access This article is licensed under a Creative Commons Attribution 4.0 International License, which permits use, sharing, adaptation, distribution and reproduction in any medium or format, as long as you give appropriate credit to the original author(s) and the source, provide a link to the Creative Commons licence, and indicate if changes were made. The images or other third party material in this article are included in the article's Creative Commons licence, unless indicated otherwise in a credit line to the material. If material is not included in the article's Creative Commons licence and your intended use is not permitted by statutory regulation or exceeds the permitted use, you will need to obtain permission directly from the copyright holder. To view a copy of this licence, visit http://creativecommons.org/licenses/by/4.0/ The Creative Commons Public Domain Dedication waiver (http://creativecommons.org/publicdomain/zero/1.0/) applies to the data made available in this article, unless otherwise stated in a credit line to the data. 


\section{Background}

Ovarian cancer is the most lethal gynecologic malignancy and the eighth leading cause of cancer deaths among women worldwide [1]. Because of the absence of effective measures for early detection, it is often diagnosed at an advanced stage and the overall 5 year survival is only about $30 \%[2,3]$. The mainstay of treatment of ovarian cancer is primary surgery aimed at complete resection of all visible tumor followed by combination chemotherapy including platinum and paclitaxel [4]. Although most patients initially respond well to primary combined treatment, about $80 \%$ relapse within 5 years [5] and eventually die because of significant intraperitoneal or lymph node metastasis.

Lymphatic spread has been reported to be a common feature and an important prognostic factor in ovarian cancer. The rate of lymph node metastasis is 44 to $53 \%$ detected by systematic lymphadenectomy (SL) in patients with disease in all International Federation of Gynecology and Obstetrics (FIGO) stages [6,7]. Although the association between pelvic or para-aortic lymph node metastasis and poor prognosis has been established [8], considerable debate has focused on whether these lymph nodes should be systematically removed during primary surgery.

The efficacy of SL on survival is controversial. Several retrospective studies have reported that SL is associated with improved survival [9-12]. However, other investigators have questioned the therapeutic efficacy of SL [13, 14]. In addition, the previous meta-analyses also have indicated that lymphadenectomy can provide a survival benefit in allstage disease [15-17]. But their statistical methods didn't employ hazards ratio (HR) and most of the studies included were retrospective whose data was not so reliable. Recently, the Lymphadenectomy in Ovarian Neoplasms (LION) trial, which was a famous and large RCT, showed that SL after maximal cytoreduction did not improve survival and may cause additional harm [18]. These results were entirely different from previous studies.

Therefore, we designed this meta-analysis including the new RCT to reevaluate the role of SL in ovarian cancer, and this is the first meta-analysis of all qualified relevant RCTs performed to date in which the postoperative complications are also analyzed.

\section{Methods}

This systematic review and meta-analysis was conducted according to the guidelines of the Preferred Reporting Items for Systematic Reviews and Meta-Analyses (PRISMA) [19]. Because all analyses were performed using data from previously published studies, ethical approval and patient consent were unnecessary. Two reviewers independently performed the literature searches, data extraction, and quality assessment, and any disagreements were resolved by discussion.

\section{Literature search and selection criteria}

The two reviewers systematically searched the PubMed, Medline, Embase, Cochrane Library, and Web of Science databases up to October 2019. The following terms were searched: Lymphadenectomy or lymph node dissection or lymph node or lymph node sampling AND ovarian cancer or ovarian tumor or ovarian neoplasm or ovarian carcinoma. Additionally, the reference lists of the identified articles and the "Related Articles" feature in PubMed were reviewed to maximize the probability of finding additional suitable papers. All English-language publications of RCTs that investigated the effects of SL in patients with ovarian cancer were included.

The exclusion criteria for the present study were as follows: (1) non-randomized clinical trials, (2) incomplete information for a quantitative analysis, (3) nonhuman models or non-English-language publications, or (4) no comparison between SL and unsystematic lymphadenectomy (USL). Two reviewers independently screened and excluded papers based on the abstracts using the inclusion and exclusion criteria; then, the fulltext articles with potentially relevant abstracts were retrieved and independently assessed according to the inclusion and exclusion checklists. All disagreements were resolved by discussion until a consensus was reached; if this failed, a third reviewer (Jinyi Tong) was consulted.

\section{Data extraction}

Two reviewers independently extracted the data from eligible primary studies and transferred them into a standard data extraction form. These data included the first author, year of publication, study design, number of participants in each group, participant age, clinical stage, definition of SL and USL, survival (OS and PFS) and complications. The primary outcome in the present meta-analysis was OS; the secondary outcome was PFS. For safety, we also examined complications rate after surgery.

\section{Quality assessment}

The quality levels of the included studies were independently assessed by two reviewers, and any disagreement was resolved through discussion and consensus. Briefly, the Cochrane Collaboration tool [20] was used to assess the risk of bias with respect to the following: selection bias (random sequence generation and allocation concealment), attrition bias (incomplete outcome data), performance and detection bias (blinding of participants, personnel and outcome assessment), reporting bias (selective reporting), and other biases (other sources of bias).

\section{Statistical analysis}

All data syntheses and analyses were performed using RevMan 5.3 software (Cochrane Collaboration; Oxford, UK). For OS and PFS, pooled hazard ratios (HR; SL vs. USL) 
with 95\% confidence intervals (CIs) were calculated; for complications rate, we calculated pooled risk ratio (RR, SL vs. USL) with $95 \%$ CI. Statistical heterogeneity was assessed using both the $\mathrm{I}^{2}$ and chi-square tests. In cases of $\mathrm{I}^{2}$ being larger than 50\%, a random-effect model was used, otherwise a fixed-effect model was used [21].

Sensitivity analyses were used to assess the stability of the results, and funnel plots were used to screen for potential publication biases.

\section{Results}

\section{Overview}

Our search strategy identified 1727 articles, 1691 of which were excluded by the title and abstract screening processes. Of the remaining 36 articles, full texts were accessed and, ultimately, four RCTs met our inclusion criteria and were included in this review [18, 22-24].
Figure 1 presents a flow chart illustrating the above search process.

\section{Description of studies}

The basic characteristics of the four studies are summarized in Table 1. These four articles are all RCTs [18, 22-24]. There are 808 patients in the SL group, and 799 patients in the USL group. The median age ranged from 50 to 60 years. Of the four trials, three studies [22-24] included both patients with macroscopically complete resection(R0) and those with residual tumors of up to $1 \mathrm{~cm}$ in diameter after surgery(R1), and the patients in one study [18] were macroscopically completely resected(R0). SL was defined as follows: (1) systematic pelvic and aortic lymphadenectomy [18]; (2) pelvic $(\geq 20)$ and para-aortic $(\geq 15)$ resected lymph nodes [23]; and (4) pelvic $(\geq 25)$ and para-aortic $(\geq 15)$ resected lymph nodes [22, 24]. And USL was defined as

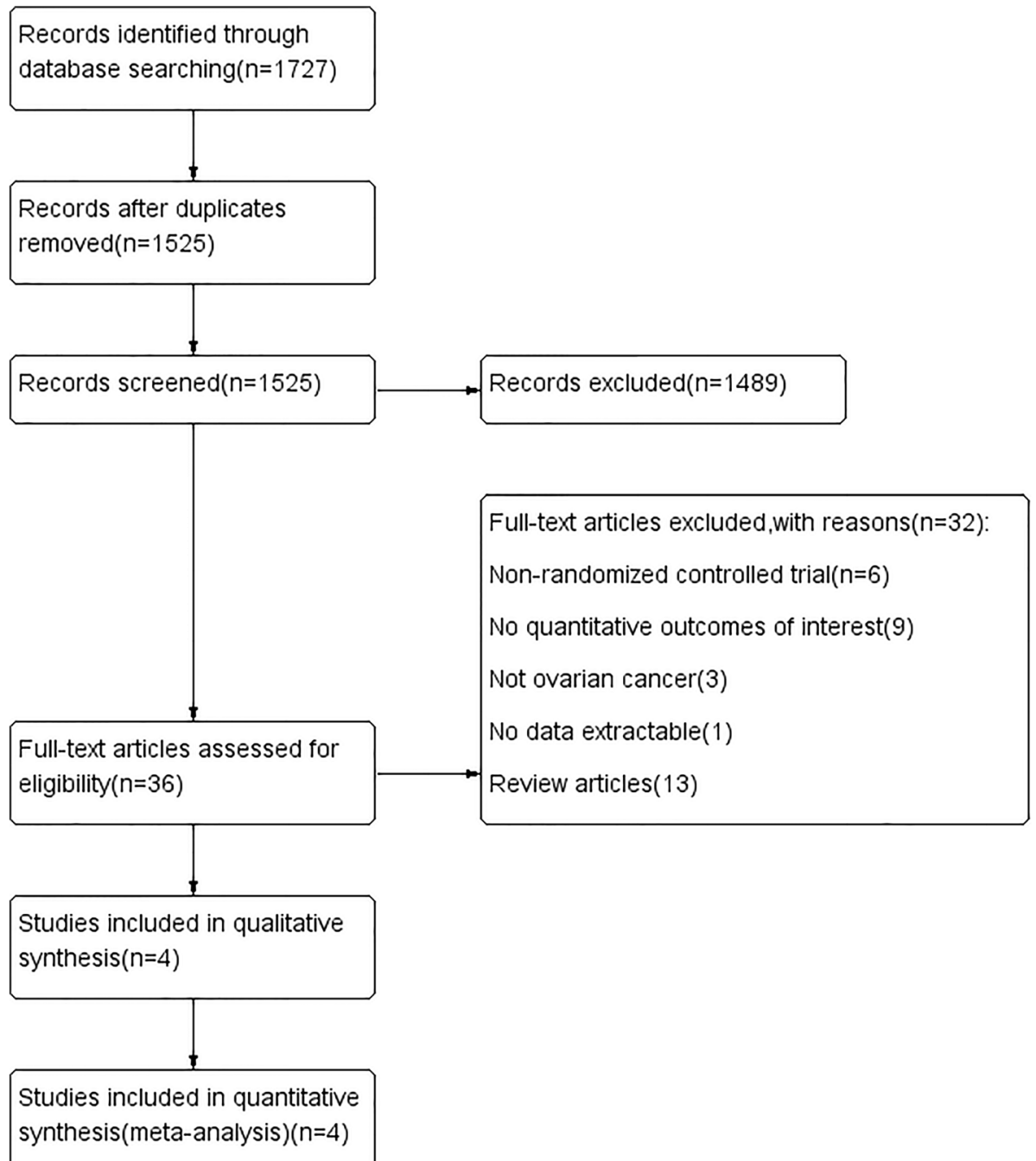

Fig. 1 Flow diagram showing selection of the studies for this meta-analysis 
Table 1 Characteristics of the studies included in the analysis

\begin{tabular}{|c|c|c|c|c|c|c|c|c|}
\hline First author (publication year) & $\begin{array}{l}\text { Study } \\
\text { design }\end{array}$ & Histology type & $\begin{array}{l}\text { FIGO } \\
\text { stage }\end{array}$ & $\begin{array}{l}\text { Debulking } \\
\text { Surgery }\end{array}$ & Group & $\begin{array}{l}\text { Number of } \\
\text { patients }\end{array}$ & $\begin{array}{l}\text { Median } \\
\text { age (y) }\end{array}$ & Definition of SL and USL \\
\hline \multirow[t]{2}{*}{ Harter (2019) [18] } & $\mathrm{RCT}$ & $\begin{array}{l}\text { Epithelial ovarian } \\
\text { cancer }\end{array}$ & $\| \mathrm{B}-\mathrm{IV}$ & RO & SL & 323 & 60 & $\begin{array}{l}\text { systematic pelvic and aortic } \\
\text { lymphadenectomy }\end{array}$ \\
\hline & & & & & USL & 324 & 60 & no lymphadenectomy \\
\hline \multirow[t]{2}{*}{ Maggioni (2006) [23] } & RCT & $\begin{array}{l}\text { Epithelial ovarian } \\
\text { cancer }\end{array}$ & $|-| \mid$ & R1 & SL & 138 & 51 & $\begin{array}{l}\text { systematic pelvic }(\geq 20) \text { and } \\
\text { aortic }(\geq 15) \text { lymphadenectomy }\end{array}$ \\
\hline & & & & & USL & 130 & 52 & $\begin{array}{l}\text { random removal of pelvic and } \\
\text { para-aortic LNs (sampling) }\end{array}$ \\
\hline \multirow[t]{2}{*}{ Panici (2005) [22] } & $\mathrm{RCT}$ & $\begin{array}{l}\text { Epithelial ovarian } \\
\text { cancer }\end{array}$ & IIIB-IV & R1 & SL & 189 & 53 & $\begin{array}{l}\text { systematic pelvic }(\geq 25) \text { and } \\
\text { aortic }(\geq 15) \text { lymphadenectomy }\end{array}$ \\
\hline & & & & & USL & 195 & 56 & bulky nodes only \\
\hline \multirow[t]{2}{*}{ Dell' Anna (2012) [24] } & $\mathrm{RCT}$ & $\begin{array}{l}\text { Epithelial ovarian } \\
\text { cancer }\end{array}$ & I-IV & R1 & $S L$ & 158 & 50 & $\begin{array}{l}\text { systematic pelvic }(\geq 25) \text { and } \\
\text { aortic }(\geq 15) \text { lymphadenectomy }\end{array}$ \\
\hline & & & & & USL & 150 & 52 & bulky nodes only \\
\hline
\end{tabular}

$R C T$ randomized controlled trial, FIGO International Federation of Gynecology and Obstetrics, $R 0$ no residual tumor, $R 1$ residual tumor $<1 \mathrm{~cm}, S L$ systematic lymphadenectomy, USL unsystematic lymphadenectomy

follows: (1) no lymphadenectomy [18]; (2) random removal of pelvic and para-aortic lymph nodes (sampling) [23]; and (3) removal of all macroscopic $(\geq 1 \mathrm{~cm})$ lymph nodes [22, 24].

\section{Quality assessment}

The quality assessments of the included RCTs are summarized in Table 2; the overall quality of the trials was determined to be good. Briefly, the randomization methods were described in all the four studies, and the allocation concealments was unclear in one study and high risk in one study, the blinding of outcome was unclear in two studies. In terms of incomplete outcome data and other bias, all four studies were considered to be low risk. Finally, the selective outcome reporting was unclear in one study.

\section{Overall survival}

All four studies, with a total number of 1607 patients, were included in the meta-analysis for OS between the SL and USL groups in all-stage disease. A fixed-effect model of analysis was used, and the result indicated that there was no significant difference in OS between SL and USL groups $(\mathrm{HR}=1.00 ; 95 \% \mathrm{CI}=0.94,1.07 ; p=$ 0.90 ; Fig. 2). In addition, heterogeneity was not observed $\left(\mathrm{I}^{2}=0 \% ; p=0.89\right)$ in this analysis.

\section{Progression-free survival}

Meta-analysis, including all four RCTs, assessing 1607 women, investigated PFS between the SL and USL groups in all-stage disease. A random-effect model of analysis was used, and it also showed no significant difference in PFS between the SL and USL groups (HR = $0.97 ; 95 \% \mathrm{CI}=0.87,1.08 ; p=0.62$; Fig. 3 ), but heterogeneity was observed $\left(\mathrm{I}^{2}=70 \% ; p=0.02\right)$.

\section{Postoperative complications}

Four RCTs all reported the number of postoperative complications in the SL and USL groups. Postoperative complications occurred in $42.6 \%$ of patients in the SL group and $28.8 \%$ of patients in the USL group. The pooled analysis revealed that postoperative complications occurred more frequently in the SL group $(\mathrm{RR}=1.50 ; 95 \% \mathrm{CI}=$ $1.34,1.68 ; p<0.00001$; Fig. 4 ). There was little heterogeneity among the studies $\left(\mathrm{I}^{2}=32 \% ; p=0.22\right)$.

\section{Sensitivity analysis and publication Bias}

The results of the sensitivity analyses for OS, PFS, and postoperative complications revealed that none of the included studies alone had an obvious impact on the direction or magnitude of the outcomes. Publication bias was evaluated using funnel plots, and the shape of the funnel plot did not provide evidence of visible

Table 2 Quality assessments for the included randomized controlled studies using the Cochrane Collaboration's tool

\begin{tabular}{|c|c|c|c|c|c|c|}
\hline Study & $\begin{array}{l}\text { Sequence } \\
\text { generation }\end{array}$ & $\begin{array}{l}\text { Allocation } \\
\text { concealment }\end{array}$ & $\begin{array}{l}\text { Blinding of outcome } \\
\text { assessment }\end{array}$ & $\begin{array}{l}\text { Incomplete } \\
\text { outcome data }\end{array}$ & $\begin{array}{l}\text { Selective } \\
\text { reporting }\end{array}$ & Other bias \\
\hline Harter (2019) [18] & Low risk & Low risk & Low risk & Low risk & Low risk & Low risk \\
\hline Dell' Anna (2012) [24] & Low risk & High risk & Unclear risk & Low risk & Low risk & Low risk \\
\hline Maggioni (2006) [23] & Low risk & Unclear risk & Low risk & Low risk & Unclear risk & Low risk \\
\hline Panici (2005) [22] & Low risk & Low risk & Unclear risk & Low risk & Low risk & Low risk \\
\hline
\end{tabular}




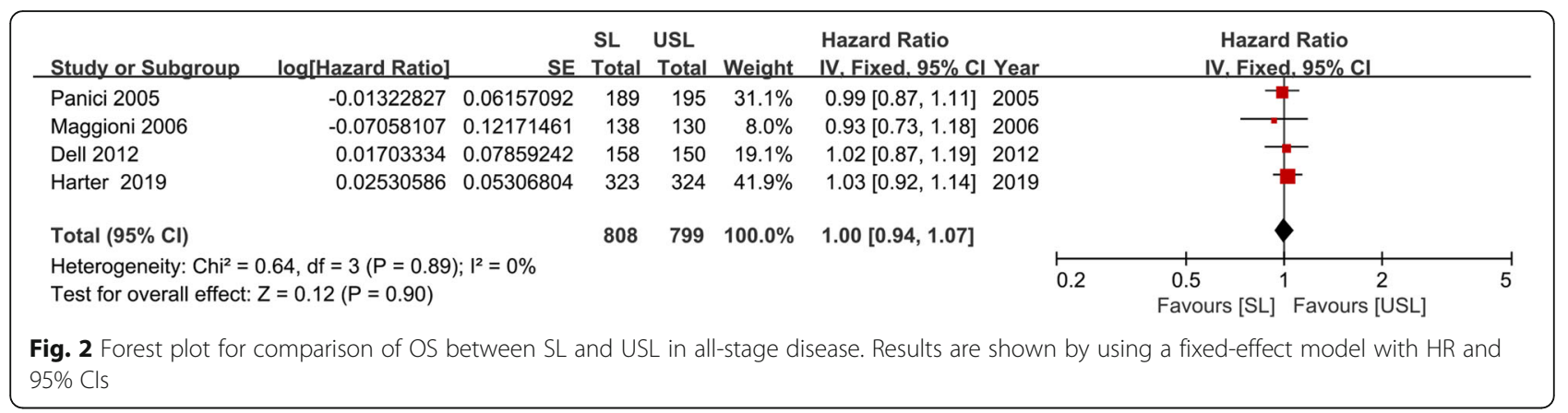

asymmetry (Fig. 5). Therefore, the present results are statistically steady and robust.

\section{Discussion}

For several decades, considerable debate has focused on whether pelvic and aortic lymph nodes should be systematically removed during ovarian cancer surgery. In this meta-analysis, we found that no significant differences in OS and PFS were observed between the SL and USL groups. It indicated that patients with ovarian cancer did not benefit from SL. In contrast, SL increased the risk of postoperative complications, hence, it resulted in treatment burden and harm to patients.

The results of our meta-analysis contradict the findings of many previous retrospective studies [10, 25-29] These analyses including large numbers of patients have suggested a benefit of lymphadenectomy [10, 25-29], but they are pone to several biases. For example, the decision as to which patients underwent radical cytoreductive procedures including SL was determined by the operating surgeon's preference. Because SL is a procedure with a considerable treatment burden, surgeons would perform SL more frequently in younger and fitter patients, whereas patients with poor performance status are more likely in a USL group. This selection bias is inherent in retrospective studies and is difficult to avoid. And it may lead to the survival advantage in SL group.

Besides, our findings are not consistent with the previous meta-analyses. In 2010, Kim et al. [15] performed a meta-analysis comparing the effect of SL and USL on
OS. And it showed that SL was efficient for improving OS in all-stage disease. Gao et al. [16] also conducted a meta-analysis in 2014, which confirmed the improvement of OS in the SL group. Besides, in 2016, another meta-analysis by J Zhou et al. [17] also demonstrated an increase in OS with SL, but no difference was found in PFS between the groups. The discrepancy between the previous meta-analyses and ours may due to differences in the included articles. In their meta-analyses, most of the studies included were observational ones, which have lower inferential strength than RCTs. And the number of subjects in these included RCTs was not large, which is not sufficient to describe the role of SL in patients with ovarian cancer. In addition, they used OR or RR to evaluate the role of SL in ovarian cancer which didn't take time-point into consideration. In our study, we used HR instead to calculate both OS and PFS which would be much better. Besides, we also evaluated the postoperative complications which were not described in previous meta-analyses but important to weigh the pros and cons of SL.

The present meta-analysis showed that women in the SL group had more postoperative complications. In all four RCTs included, it was showed that SL significantly prolonged operating time, increased blood loss and the percentage of patients requiring blood transfusion. Because lymphadenectomy is always in close proximity to large vascular, the threat of intraoperative hemorrhage is always present. The systematic pelvic and especially para-aortic lymphadenectomy are considered to be the

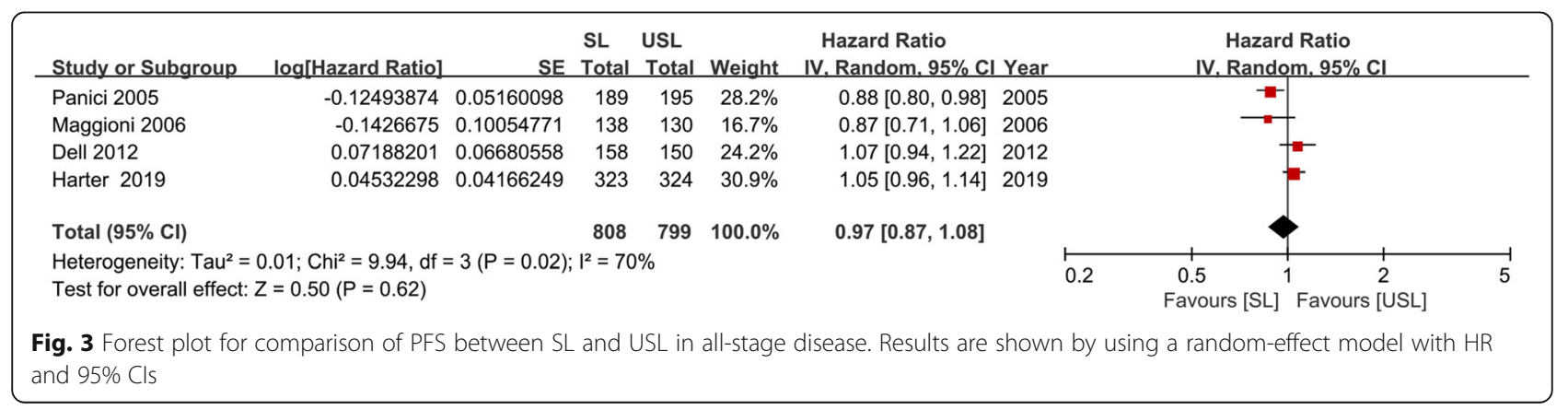




\begin{tabular}{|c|c|c|c|c|c|c|c|c|c|c|}
\hline Study or Subgroup & $\begin{array}{r}\text { SL } \\
\text { Events }\end{array}$ & Total & $\begin{array}{c}\text { USL } \\
\text { Events }\end{array}$ & Total & Weight & $\begin{array}{c}\text { Risk Ratio } \\
\text { M-H, Fixed. } 95 \% \mathrm{Cl}\end{array}$ & & $\begin{array}{r}\text { Risk R } \\
\text { M-H. Fixed }\end{array}$ & $\begin{array}{l}\text { Ratio } \\
\text { d. } 95 \% \mathrm{Cl}\end{array}$ & \\
\hline Harter 2019 & 254 & 323 & 180 & 324 & $78.3 \%$ & $1.42[1.26,1.58]$ & & & & \\
\hline Panici 2005 & 60 & 189 & 39 & 195 & $16.7 \%$ & $1.59[1.12,2.25]$ & & & $\rightarrow$ & \\
\hline Maggioni 2006 & 16 & 138 & 8 & 130 & $3.6 \%$ & $1.88[0.83,4.25]$ & & & & \\
\hline Dell 2012 & 14 & 158 & 3 & 150 & $1.3 \%$ & $4.43[1.30,15.11]$ & & & & \\
\hline Total $(95 \% \mathrm{Cl})$ & & 808 & & 799 & $100.0 \%$ & $1.50[1.34,1.68]$ & & & 1 & \\
\hline Total events & 344 & & 230 & & & & & & & \\
\hline $\begin{array}{l}\text { Heterogeneity: } \mathrm{Chi}^{2}= \\
\text { Test for overall effect: }\end{array}$ & $\begin{array}{l}.44, d f=3 \\
=7.03(P\end{array}$ & $\begin{array}{l}3(P=C \\
P<0.0\end{array}$ & $\begin{array}{l}.22) ; 1^{2}= \\
0001)\end{array}$ & $32 \%$ & & & 0.01 & $\begin{array}{ll}0.1 & 1 \\
\text { Favours [SL] }\end{array}$ & $\begin{array}{c}10 \\
\text { Favours [USL] }\end{array}$ & 100 \\
\hline
\end{tabular}

most complex and challenging technical requiring a higher surgical expertise and skill to avoid unnecessary morbidity. However, even in the hands of experienced surgeons, surgical morbidity related to lymphocyst formation, vascular events, ileus, and prolonged hospitalization may complicate a patient's journey. And the less frequent complications such as injury to nerves, ureters and bowels may also impact the quality of patients' life [7, 30].

It is well known that the prognosis of early ovarian cancer (EOC) is strikingly different from advanced ovarian cancer (AOC), EOC has a 10-year survival rate of over $80 \%$ [31], whereas AOC has a 5-year survival rate of approximately $30 \%$ [32]. So we discuss them separately. In EOC, SL is required for accurate staging and adequate treatment. According to the FIGO, the presence of lymph node involvement in the early stages of ovarian cancer raises the disease stage to $3 \mathrm{~A} 1$ and requires adjuvant therapy. In addition, accurate staging in very early-stage disease may prevent unnecessary postoperative chemotherapy. Besides, SL has a proven prognostic value, lymph node metastasis is related to poor prognosis. Above all, although the effect of SL on survival is still not clear, it is paramount in the management of EOC. In AOC, the role of lymphadenectomy is therapeutic with the purpose of removing as much tumor as possible. Theoretically, the pharmacologic sanctuary hypothesis suggests that nodal metastases of ovarian cancer may be less sensitive to systemic chemotherapy due to diminished blood supply [33]. And it further implies that SL may be a favorable prognostic factor in patients with AOC who have an increased risk of occult lymph node metastasis [34]. Actually, the randomized LION trial showed patients with AOC do not benefit from SL, but

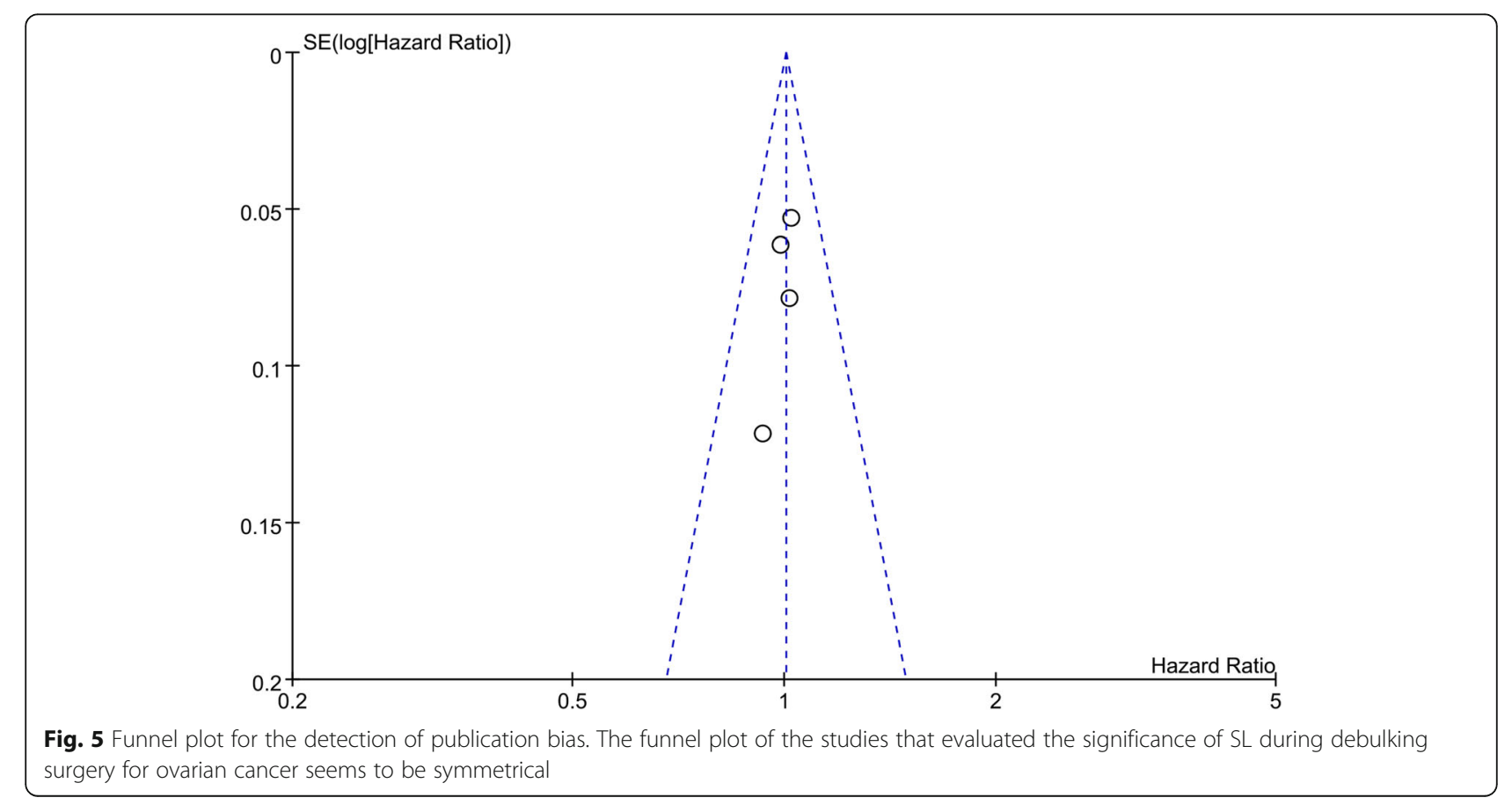


experience a significantly higher rate of intraoperative and postoperative complications [18]. Thus, it seems that there is no reason to perform lymphadenectomy in this subgroup of patients.

Several limitations of our study should be considered. Firstly, heterogeneity may be present because the definition of NSL was diverse among the included articles. Additionally, the diameters of residual tumors were different, including macroscopically complete resection and up to $1 \mathrm{~cm}$. Secondly, although we attempted to perform an extensive literature search to obtain all published studies, there were only 4 relevant RCTs. For this reason, we were unable to conduct subgroup analyses with regard to cancer stage, histological type, patient age or country of origin. Thirdly, we were not able to perform a search of unpublished studies, studies with negative results were less likely to be published, and thus the results of our study were limited by the inclusion of published data only. Finally, only English-language studies were included in this meta-analysis which may have introduced a language bias. However, despite these limitations, the quality of evidence was high which was about the survival impact of SL and its risk of complication.

\section{Conclusion}

The present findings showed that SL during optimal debulking surgery for ovarian cancer was not associated with better outcomes than USL and was associated with a higher incidence of postoperative complications. SL should be reconsidered as a standard practice during optimal debulking surgery for ovarian cancer, and more well-designed studies are needed.

\section{Abbreviations}

RCT: Randomized controlled trial; OS: Overall survival; PFS: Progression-free survival; HR: Hazard ratio; Cl: Confidence interval; RR: Risk ratio; SL: Systematic Iymphadenectomy; USL: Unsystematic lymphadenectomy; FIGO: International Federation of Gynecology and Obstetrics; LION: Lymphadenectomy in Ovarian Neoplasms; PRISMA: Preferred Reporting Items for Systematic Reviews and Meta-Analyses; EOC: Early ovarian cancer; AOC: Advanced ovarian cancer

\section{Acknowledgements}

We would like to thank all authors who provided published data for our meta-analysis.

\section{Authors' contributions}

JYT and QQL conceived and designed the experiments. QQL and JL extracted and analyzed data. QQL and WCL were the statisticians who confirmed the analysis of this study. QQL and SX wrote the manuscript. All authors read and approved the final manuscript.

\section{Funding}

None.

\section{Availability of data and materials}

All data generated or analyzed during this study are included in this published article [and its supplementary information files].
Ethics approval and consent to participate

Not applicable.

\section{Consent for publication}

Not applicable.

\section{Competing interests}

The authors declare that they have no competing interests.

\section{Author details}

'Department of Gynecology, Affiliated Hangzhou First People's Hospital, Zhejiang University School of Medicine, 261 Huansha Rd, Hangzhou City 310006, Zhejiang Province, China. ${ }^{2}$ Department of Neurosurgery, First Affiliated Hospital, School of Medicine, Zhejiang University, Hangzhou 310003, Zhejiang, China.

Received: 25 November 2019 Accepted: 22 April 2020

Published online: 08 May 2020

\section{References}

1. Ferlay J, Colombet M, Soerjomataram I, Mathers C, Parkin DM, Pineros M, Znaor A, Bray F. Estimating the global cancer incidence and mortality in 2018: GLOBOCAN sources and methods. Int J Cancer. 2019;144(8):1941-53.

2. Heintz AP, Odicino F, Maisonneuve P, Quinn MA, Benedet JL, Creasman WT, Ngan HY, Pecorelli S, Beller U. Carcinoma of the ovary. FIGO 26th Annual Report on the Results of Treatment in Gynecological Cancer. Int J Gynaecol Obstet. 2006;95(Suppl 1):S161-92.

3. Jemal A, Tiwari RC, Murray T, Ghafoor A, Samuels A, Ward E, Feuer EJ, Thun MJ, American Cancer S. Cancer statistics, 2004. CA Cancer J Clin. 2004;54(1): 8-29.

4. du Bois A, Quinn M, Thigpen T, Vermorken J, Avall-Lundqvist E, Bookman M, Bowtell D, Brady M, Casado A, Cervantes A, et al. 2004 Consensus statements on the management of ovarian cancer: final document of the 3rd international gynecologic Cancer intergroup ovarian Cancer consensus conference (GCIG OCCC 2004). Ann Oncol. 2005;16(Suppl 8):viii7-viii12.

5. Mor G, Alvero A. The duplicitous origin of ovarian cancer. Rambam Maimonides Med J. 2013;4(1):e0006

6. Harter P, Gnauert K, Hils R, Lehmann TG, Fisseler-Eckhoff A, Traut A, du Bois A. Pattern and clinical predictors of lymph node metastases in epithelial ovarian cancer. Int J Gynecol Cancer. 2007;17(6):1238-44.

7. Morice P, Joulie F, Camatte S, Atallah D, Rouzier R, Pautier P, Pomel C, Lhomme C, Duvillard P, Castaigne D. Lymph node involvement in epithelial ovarian cancer: analysis of 276 pelvic and paraaortic lymphadenectomies and surgical implications. J Am Coll Surg. 2003;197(2):198-205.

8. Takeshima N, Hirai Y, Umayahara K, Fujiwara K, Takizawa K, Hasumi K. Lymph node metastasis in ovarian cancer: difference between serous and nonserous primary tumors. Gynecol Oncol. 2005;99(2):427-31.

9. Aletti GD, Dowdy S, Podratz KC, Cliby WA. Role of lymphadenectomy in the management of grossly apparent advanced stage epithelial ovarian cancer. Am J Obstet Gynecol. 2006;195(6):1862-8.

10. Chan JK, Urban R, Hu JM, Shin JY, Husain A, Teng NN, Berek JS, Osann K, Kapp DS. The potential therapeutic role of lymph node resection in epithelial ovarian cancer: a study of 13918 patients. Br J Cancer. 2007;96(12): 1817-22.

11. du Bois A, Reuss A, Harter P, Pujade-Lauraine E, Ray-Coquard I, Pfisterer J. Arbeitsgemeinschaft Gynaekologische Onkologie Studiengruppe O, Groupe d'Investigateurs Nationaux pour l'Etude des cancers O: potential role of lymphadenectomy in advanced ovarian cancer: a combined exploratory analysis of three prospectively randomized phase III multicenter trials. J Clin Oncol. 2010;28(10):1733-9.

12. Rungruang BJ, Miller A, Krivak TC, Horowitz NS, Rodriguez N, Hamilton CA, Backes FJ, Carson LF, Friedlander M, Mutch DG, et al. What is the role of retroperitoneal exploration in optimally debulked stage IIIC epithelial ovarian cancer? An NRG oncology/gynecologic oncology group ancillary data study. Cancer. 2017;123(6):985-93.

13. Parazzini F, Valsecchi $G$, Bolis $G$, Guarnerio $P$, Reina $S$, Polverino $G$, Silvestri $D$. Pelvic and paraortic lymph nodal status in advanced ovarian cancer and survival. Gynecol Oncol. 1999;74(1):7-11.

14. Abe A, Furumoto $H$, Irahara $M$, Ino H, Kamada M, Naka O, Sasaki M, Kagawa T, Okitsu O, Kushiki N. The impact of systematic Para-aortic and pelvic 
lymphadenectomy on survival in patients with optimally debulked ovarian cancer. J Obstet Gynaecol Res. 2010;36(5):1023-30.

15. Kim HS, Ju W, Jee BC, Kim YB, Park NH, Song YS, Kim SC, Kang SB, Kim JW. Systematic lymphadenectomy for survival in epithelial ovarian cancer: a meta-analysis. Int J Gynecol Cancer. 2010;20(4):520-8.

16. Gao J, Yang X, Zhang Y. Systematic lymphadenectomy in the treatment of epithelial ovarian cancer: a meta-analysis of multiple epidemiology studies. Jpn J Clin Oncol. 2015;45(1):49-60.

17. Zhou J, Shan G, Chen Y. The effect of lymphadenectomy on survival and recurrence in patients with ovarian cancer: a systematic review and metaanalysis. Jpn J Clin Oncol. 2016;46(8):718-26.

18. Harter P, Sehouli J, Lorusso D, Reuss A, Vergote I, Marth C, Kim JW, Raspagliesi F, Lampe B, Aletti G, et al. A randomized trial of lymphadenectomy in patients with advanced ovarian neoplasms. N Engl J Med. 2019;380(9):822-32

19. Moher D, Liberati A, Tetzlaff J, Altman DG, Group P. Preferred reporting items for systematic reviews and meta-analyses: the PRISMA statement. Ann Intern Med. 2009;151(4):264-9 W264.

20. Higgins JP, Altman DG, Gotzsche PC, Juni P, Moher D, Oxman AD, Savovic J, Schulz KF, Weeks L, Sterne JA, et al. The Cochrane Collaboration's tool for assessing risk of bias in randomised trials. Bmj. 2011;343:d5928.

21. Higgins JP, Thompson SG, Deeks JJ, Altman DG. Measuring inconsistency in meta-analyses. Bmj. 2003;327(7414):557-60.

22. Panici PB, Maggioni A, Hacker N, Landoni F, Ackermann S, Campagnutta E, Tamussino K, Winter R, Pellegrino A, Greggi S, et al. Systematic aortic and pelvic lymphadenectomy versus resection of bulky nodes only in optimally debulked advanced ovarian cancer: a randomized clinical trial. J Natl Cancer Inst. 2005;97(8):560-6.

23. Maggioni A, Benedetti Panici P, Dell'Anna T, Landoni F, Lissoni A, Pellegrino A, Rossi RS, Chiari S, Campagnutta E, Greggi S, et al. Randomised study of systematic lymphadenectomy in patients with epithelial ovarian cancer macroscopically confined to the pelvis. Br J Cancer. 2006;95(6):699-704.

24. Dell'Anna T, Signorelli M, Benedetti-Panici P, Maggioni A, Fossati R, Fruscio R, Milani R, Bocciolone L, Buda A, Mangioni C, et al. Systematic lymphadenectomy in ovarian cancer at second-look surgery: a randomised clinical trial. Br J Cancer. 2012;107(5):785-92.

25. Chang SJ, Bristow RE, Ryu HS. Prognostic significance of systematic lymphadenectomy as part of primary debulking surgery in patients with advanced ovarian cancer. Gynecol Oncol. 2012;126(3):381-6.

26. Paik ES, Shim M, Choi HJ, Lee YY, Kim TJ, Lee JW, Kim BG, Bae DS, Choi CH. Impact of lymphadenectomy on survival after recurrence in patients with advanced ovarian cancer without suspected lymph node metastasis. Gynecol Oncol. 2016;143(2):252-7.

27. Eoh KJ, Lee JY, Yoon JW, Nam EJ, Kim S, Kim SW, Kim YT. Role of systematic lymphadenectomy as part of primary debulking surgery for optimally cytoreduced advanced ovarian cancer: reappraisal in the era of radical surgery. Oncotarget. 2017;8(23):37807-16.

28. Matsuo K, Machida H, Mariani A, Mandalbaum RS, Gaser GE, Gostout BS, Roman LD, Wight ID. Adequate petic lymphadenectomy and survid of women with early stage epitheili ovarian cancer.J Gnecol Oncol 20182951) 69

29. Ercelep O, Ozcelik M, Gumus M. Association of lymphadenectomy and survival in epithelial ovarian cancer. Curr Probl Cancer. 2019:43(2):151-9.

30. Legge F, Petrillo M, Adamo V, Pisconti S, Scambia G, Ferrandina G. Epithelial ovarian cancer relapsing as isolated lymph node disease: natural history and clinical outcome. BMC Cancer. 2008;8:367.

31. Trimbos B, Timmers P, Pecorelli S, Coens C, Ven K, van der Burg M, Casado A. Surgical staging and treatment of early ovarian cancer: long-term analysis from a randomized trial. J Natl Cancer Inst. 2010;102(13):982-7.

32. Holschneider $\mathrm{CH}$, Berek JS. Ovarian cancer: epidemiology, biology, and prognostic factors. Semin Surg Oncol. 2000;19(1):3-10.

33. Morice P, Joulie F, Rey A, Atallah D, Camatte S, Pautier P, Thoury A, Lhomme C, Duvillard P, Castaigne D. Are nodal metastases in ovarian cancer chemoresistant lesions? Analysis of nodal involvement in 105 patients treated with preoperative chemotherapy. Eur J Gynaecol Oncol. 2004;25(2):169-74.

34. Berek JS. Lymph node-positive stage IIIC ovarian cancer: a separate entity? Int J gynecol Cancer. 2009;19(Suppl 2):S18-20.

\section{Publisher's Note}

Springer Nature remains neutral with regard to jurisdictional claims in published maps and institutional affiliations.

Ready to submit your research? Choose BMC and benefit from:

- fast, convenient online submission

- thorough peer review by experienced researchers in your field

- rapid publication on acceptance

- support for research data, including large and complex data types

- gold Open Access which fosters wider collaboration and increased citations

- maximum visibility for your research: over $100 \mathrm{M}$ website views per year

At BMC, research is always in progress.

Learn more biomedcentral.com/submissions 